Tropical Journal of Pharmaceutical Research December 2013; 12 (6): 869-876

ISSN: $1596-5996$ (print); 1596-9827 (electronic) (c) Pharmacotherapy Group, Faculty of Pharmacy, University of Benin, Benin City, 300001 Nigeria.

All rights reserved.

Available online at http://www.tjpr.org Original Research Article http://dx.doi.org/10.4314/tjpr.v12i6.2

\title{
Design Optimization and Evaluation of Gastric Floating Matrix Tablet of Glipizide
}

\author{
Lalit Singh ${ }^{1^{*}}$, Arun Nanda ${ }^{2}$, Saurabh Sharma ${ }^{3}$ and Vijay Sharma ${ }^{1}$ \\ ${ }^{1}$ Department of Pharmaceutics, SRMSCET, Pharmacy, Bareilly, Uttar Pradesh, ${ }^{2}$ Department of Pharmaceutical Sciences MDU, \\ Rohtak, Haryana, ${ }^{3}$ Vivek College of Technical Education, Bijnor, Uttar Pradesh, India.
}

*For correspondence: Email: lalit_4u78@rediffmail.com; Tel: +919412602860

Received: 5 October 2012

Revised accepted: 11 October 2013

\begin{abstract}
Purpose: To formulate an optimized gastric floating drug delivery system (GFDDS) containing glipizide with carbomers and cellulosic polymers.

Method: Central composite design (CCD) was employed in formulating the GFDDS using hydroxypropyl methylcellulose K4M (HPMC K4M) (A) and Carbopol 934P (CP934P) (B), as independent variables. Floating lag time (FLT), total floating time (TFT) and time required to release 50 $\%$ of the drug $\left(T_{50}\right)$ were selected as dependent variables. The dissolution data obtained were fitted to various release models and the floating profiles of the formulations analyzed.

Results: HPMC K4M loading clearly enhanced floating properties while CP934P showed negative effect on floating properties but was helpful in controlling drug release. The quadratic mathematical model developed was used to predict optimum formulations. The computer optimization process, contour plots and response surface plots predicted the concentration of independent variables $A$ and $B$ to be 47.32 and $8.4 \mathrm{mg}$, respectively, for maximum TFT and $T_{50}$ at the same time for least FLT. Predicted concentration of independent variables showed the same results experimentally, with -0.75 1.47 percentage errors.

Conclusion: CCD demonstrated the role of the derived equations, contour plots and response surface plots in predicting the values of independent variables for the preparation and optimization of glipizide gastric floating matrix tablet.
\end{abstract}

Keywords: Effervescent, Floating tablet, Design of Experiment, Release kinetics, Central composite design, Optimization.

Tropical Journal of Pharmaceutical Research is indexed by Science Citation Index (SciSearch), Scopus, International Pharmaceutical Abstract, Chemical Abstracts, Embase, Index Copernicus, EBSCO, African Index Medicus, JournalSeek, Journal Citation Reports/Science Edition, Directory of Open Access Journals (DOAJ), African Journal Online, Bioline International, Open-J-Gate and Pharmacy Abstracts

\section{INTRODUCTION}

The challenge in developing controlled release system is not only in sustaining the release but also to prolong the retention of dosage form in the stomach or the upper small intestine until all the drug is completely released in the desired time period [1,2]. Approaches proposed to control the gastric residence of delivery systems in the upper gastrointestinal tract (GIT) include floating drug delivery systems (FDDS) [3-5], high-density [6,7], mucoadhesive [8, 9], swelling and expanding [10], modified shape and other delayed gastric devices $[2,11,12]$.

A minimum growth of $9 \%$ per year had been proposed for this market since 2003 [13], as these offers several advantages, including improved patient compliance, better therapeutic efficiency, potential for patentability, and extending the product life-cycle. Extendedrelease stomach retentive dosage forms are also 
desirable for drugs with a narrow absorption window, stability and solubility problems in the intestinal or colonic environment, and drugs that are locally acting in the stomach [3]. A major drawback for this delivery device is that it cannot be employed in the formulation of drugs which cannot be well absorbed throughout the GIT [1416]. Glipizide is an anti-diabetic drug [17] which is effective in the management of type- II diabetes mellitus. The recommended adult dose is $5 \mathrm{mg}$ twice daily (or) $10 \mathrm{mg}$ once daily. Absorption is in the stomach, and short biological half-life (ranging from 3.5 to $4 \mathrm{~h}$ ) following oral administration, Further, its short half-life $(3.5 \mathrm{~h})$, low dose (5 - $20 \mathrm{mg}$ ), narrow absorption window (stomach), high physico-chemical stability etc. make glipizide an ideal drug for floating matrix formulation [18]. These gastro-retentive systems continuously release the drug before it reaches the absorption window, thus ensuring optimal bioavailability [19].

\section{EXPERIMENTAL}

\section{Materials}

Glipizide was obtained as gift sample from USV Ltd (India). HPMC K4M, (ZydusCadila, India), CP934P (Noveon, India), sodium bicarbonate (Merck, Germany) magnesium stearate, talc and microcrystalline cellulose (SD Fine, India) were also used in the study. All other chemicals used were of analytical grade and used as received. Double distilled water was used in the study.

\section{Central composite design (CCD)}

CCD with $\alpha=1$ was employed as per the standard protocol. In the study independent variables were concentration of HPMC K4M (A) and CP934P (B) and dependent variables included total floating time (TFT), floating lag time $(F L T)$, and time for $50 \%$ release $\left(T_{50}\right)$. Tables 1 summarize an account of the all experimental runs, coded and actual levels of independent variables.

\section{Preparation of floating tablets}

Tablets were formulated using HPMC K4M and CP934P polymers for floating and release rate control. Sodium bicarbonate was added as a gas-generating agent $\left(\mathrm{CO}_{2}\right)$ in the presence of gastric fluid. Glipizide was mixed with the required quantities of HPMC K4M, CP 934P and Sodium bicarbonate by geometric mixing then mixture was blended with microcrystalline cellulose (q.s. $200 \mathrm{mg}$ ), magnesium stearate $1 \%$ and talc $2 \%$, and further mixed for additional 2-3 min. Then $200 \mathrm{mg}$ tablets containing $10 \mathrm{mg}$ glipizide were prepared by direct compression Minipress-I, 16 station rotatory tableting machine (Rimek Karnawati, India) using 8-mm flat face punch. Compression force was adjusted for hardness in the range of $3.5-4.5 \mathrm{~kg} / \mathrm{cm}^{2}$. The batches of 25 tablets were prepared for each batch of all the experimental runs (Table 1).

Table 1: Central composite design and level of independent variables

\begin{tabular}{ccccc}
\hline Formulation code & \multicolumn{2}{c}{ Coded value } & \multicolumn{2}{c}{ Actual value } \\
\cline { 2 - 5 } & Factor $\boldsymbol{A}$ & Factor $\boldsymbol{B}$ & Factor A(mg) & Factor $\boldsymbol{B}(\mathbf{m g})$ \\
\hline F1 & -1 & -1 & 34 & 6 \\
F2 & -1 & 0 & 34 & 9 \\
F3 & -1 & +1 & 34 & 12 \\
F4 & 0 & -1 & 43 & 6 \\
F5 & 0 & 0 & 43 & 9 \\
F6 & 0 & +1 & 43 & 6 \\
F7 & +1 & -1 & 52 & 9 \\
F8 & +1 & 0 & 52 & 12 \\
F9 & +1 & +1 & 52 & 9 \\
F10 & 0 & 0 & 43 & 9 \\
F11 & 0 & 0 & 43 & 9 \\
F12 & 0 & 0 & 43 & 9 \\
F13 & 0 & 0 & 43 & \\
\hline
\end{tabular}


Microcrystalline cellulose was used as a filler to adjust each tablet weight to $200 \mathrm{mg}$ because it does not interfere with the floating property of the tablet due to its low bulk density [21].

\section{In-vitro buoyancy studies}

Buoyancy studies were done to determine FLT and TFT according to the method described by Rosa et al [22]. The tablets were placed in a 100 $\mathrm{ml}$ beaker containing $0.1 \mathrm{~mol} / \mathrm{L}$ of $\mathrm{HCl}$. The time required for the tablet to rise to the surface and float was taken as the FLT and TFT, the time during which tablet remains buoyant was recorded.

\section{In-vitro swelling ability}

Single tablet was weighed $\left(\mathrm{W}_{1}\right)$ and placed in a glass beaker with $200 \mathrm{ml}$ of $0.1 \mathrm{~N} \mathrm{HCl}$, and maintained in a water bath at $37.0 \pm 0.5{ }^{\circ} \mathrm{C}$. At regular time intervals, the tablet was removed from beaker and the excess surface liquid was carefully removed with filter paper. The swollen tablet was weighed again $\left(\mathrm{W}_{2}\right)$ [23]. The swelling index (SI) was calculated using Eq 1.

$S I=\left[\left(W_{2}-W_{1}\right) W_{1}{ }^{*} 100\right.$

\section{In-vitro dissolution studies}

The release rate of glipizide from floating matrix tablets $(n=6)$ was determined according to USP XXIV using type II apparatus (Electrolab, TDT$08 \mathrm{~L}$, India). The dissolution test was performed using $900 \mathrm{~mL}$ of $0.1 \mathrm{~mol} \mathrm{~L}^{-1} \mathrm{HCl}$ at $37 \pm 0.5^{\circ} \mathrm{C}$ and $50 \mathrm{rpm}$ [24]. Samples $(5 \mathrm{~mL})$ were withdrawn from the dissolution apparatus and replaced with fresh medium. The samples were filtered through a $0.45 \mu \mathrm{m}$ membrane and diluted

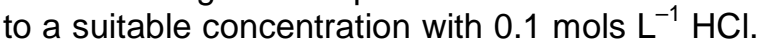
Absorbance of samples were measured at 274 nm (Shimadzu UV-1800, Japan) [25] and Cumulative drug release was calculated. The FLT and TFT of the tablets were measured during dissolution studies.

\section{Statistical analysis and optimization data}

Drug release data were analyzed using ZOREL software [26] which have in-built provisions for applying the correction factor for volume and drug losses during sampling [27].

Based on phenomenological analysis, the type of release was predicted, i.e., whether Fickian, nonFickian or zero-order. The value of $T_{50}$ was calculated using Stineman interpolation option of the Graph 2.0 software (M/s Micromath Inc., Saint Louis, USA).
Drug release data were subjected to various release models, including Higuchi model (Eq 2), which indicates whether the drug release mechanism deviates from Fick's laws and shows anomalous behaviour [28].

$\mathrm{Q}=\mathrm{K}_{\mathrm{H}} \mathrm{t}^{1 / 2}$

where, $Q$ is the amount of drug release at time $t$, and $K_{H}$ is the Higuchi rate constant.

The dissolution data was also fitted to Koresmeyer model which is used to describe drug release behaviour from polymer systems (Eqs 3 and 4) [29].

$\mathrm{Mt} / \mathrm{Ma}=\mathrm{k} \cdot \mathrm{t}^{\mathrm{n}}$.

$\log (M t / M \alpha)=\log K+n \log t$

where 'Mt' is the amount of the drug release at time ' $t$ ', 'Ma' is the amount of drug release after infinite time and ' $\mathrm{K}$ ' is a release rate constant incorporating structural and geometric characteristic of the tablet and ' $n$ ' is the diffusion exponent indications for release mechanism.

For the studied design, the multiple linear regression analysis (MLRA) method was applied using Design Expert 6.0.6 (Stat-Ease, Minneapolis, USA) software to fit full second order polynomial equation (Eq 4) with added interaction terms to correlate the studied responses with the examined variables.

The polynomial regression results were demonstrated for the studied responses. Finally, the prognosis of optimum formulation was conducted using a two-stage brute force technique using MS-Excel spread sheet software. First, a feasible space was located and second, an exhaustive grid search was conducted to predict the possible solutions. Four formulations were selected as the confirmatory check-points to validate by response surface methodology (RSM). The observed and predicted responses were critically compared. Linear correlation plots were constructed for the chosen four optimized formulations, and the percent bias (prediction error) was calculated with respect to the observed responses.

\section{RESULTS}

Oral floating controlled drug delivery of glipizide was developed and optimized using mixture of HPMC K4M and CP934P which were found suitable for obtaining directly compressible matrix tablet with suitable technological properties and well reproducible drug release profiles. For optimization, preliminary trials were 
carried out using different concentrations of HPMC K4M and CP934P to shortlist the levels.

\section{Drug content and physical evaluation}

The physical parameters of the compressed tablets were found within the specifications. As the assayed drug content in formulations ranges between $98.2 \%$ and $102.7 \%$, weight variation between $198.22 \mathrm{mg}$ and $201.1 \mathrm{mg}$. Hardness also has an effect on the floating and disintegration thus dissolution, it was ranging between 4.05 to $4.5 \mathrm{~kg} / \mathrm{cm}^{2}$. Friability of all batches was between $0.44 \% \mathrm{w} / \mathrm{w}$ to $0.86 \% \mathrm{w} / \mathrm{w}$ i.e. less than the limit of $1 \% \mathrm{w} / \mathrm{w}$. The swelling index results of all batches were found between $0.45-0.82$ up to $6 \mathrm{~h}$. All these results are shown in Table 2.

\section{Tablet floating behaviour}

TFT for all formulation ranged from 9.28 - 20.65 $\mathrm{h}$ while FLT of all formulations was within the range 5.2 - $34.2 \mathrm{~s}$ (Table 2).

\section{Drug release}

Table 3 shows the various the dissolution parameters for the matrix formulations.

The drug release data shows that the values of release rate exponent $(n)$, ranged between 0.4642 and 0.4841 drug released from all the formulations up to $12 \mathrm{~h}$ ranged between 83.69 and $88.8 \%$ and it is clear from the results that the release tended to decrease with increase in

Table 2: Physicochemical characteristics of floating glipizide tablets (mean $\pm S D, n=6$ )

\begin{tabular}{|c|c|c|c|c|c|c|c|}
\hline $\begin{array}{l}\text { Batch } \\
\text { code }\end{array}$ & $\begin{array}{l}\text { Mean tablet } \\
\text { variation } \\
(\mathrm{mg})\end{array}$ & $\begin{array}{l}\text { Hardness } \\
\left(\mathrm{kg} / \mathrm{cm}^{2}\right)\end{array}$ & $\begin{array}{l}\text { Friability } \\
(\%)\end{array}$ & $\begin{array}{l}\text { Assay } \\
(\%)\end{array}$ & $\begin{array}{l}\text { Floating } \\
\text { time (h) }\end{array}$ & $\begin{array}{l}\text { Floating } \\
\text { lag-time } \\
\text { (s) }\end{array}$ & $\begin{array}{l}\text { Swelling } \\
\text { index after } \\
6 \mathrm{~h} \\
\end{array}$ \\
\hline $\mathrm{F} 1$ & $200.15 \pm 1.04$ & $4.3 \pm 0.2$ & $0.6 \pm 0.029$ & $99.9 \pm 1.04$ & $11.2 \pm 0.28$ & $23.7 \pm 0.6$ & 0.45 \\
\hline $\mathrm{F} 2$ & $199.75 \pm 1.52$ & $4.2 \pm 0.5$ & $0.57 \pm 0.13$ & $99.75 \pm 1.12$ & $10.05 \pm 0.28$ & $26.4 \pm 1.5$ & 0.47 \\
\hline F3 & $200.75 \pm 1.36$ & $4.2 \pm 0.4$ & $0.69 \pm 0.04$ & $100.0 \pm 1.00$ & $9.0 \pm 0.28$ & $33.2 \pm 2.0$ & 0.50 \\
\hline $\mathrm{F} 4$ & $200.53 \pm 0.50$ & $4.1 \pm 0.2$ & $0.79 \pm 0.13$ & $99.9 \pm 1.47$ & $14.45 \pm 0.76$ & $18.7 \pm 1.1$ & 0.62 \\
\hline F5 & $199.66 \pm 0.90$ & $4.1 \pm 0.15$ & $0.76 \pm 0.07$ & $99.9 \pm 1.00$ & $13.1 \pm 0.28$ & $20.4 \pm 1.5$ & 0.65 \\
\hline F6 & $200.35 \pm 0.57$ & $4.1 \pm 0.2$ & $0.78 \pm 0.13$ & $99.75 \pm 2.08$ & $11.9 \pm 0.28$ & $25.1 \pm 2.6$ & 0.68 \\
\hline F7 & $199.85 \pm 1.26$ & $4.0 \pm 0.2$ & $0.75 \pm 0.15$ & $99.45 \pm 1.25$ & $20.15 \pm 0.50$ & $5.1 \pm 1.0$ & 0.76 \\
\hline F8 & $199.61 \pm 0.23$ & $4.2 \pm 0.05$ & $0.59 \pm 0.076$ & $101.00 \pm 0.5$ & $19.05 \pm 0.28$ & $5.7 \pm 0.6$ & 0.78 \\
\hline F9 & $198.86 \pm 0.64$ & $4.2 \pm 0.2$ & $0.69 \pm 0.09$ & $100.1 \pm 0.28$ & $18.0 \pm 0.57$ & $6.4 \pm 0.6$ & 0.82 \\
\hline F10 & $200.2 \pm 0.40$ & $4.1 \pm 0.15$ & $0.76 \pm 0.1$ & $100.5 \pm 0.50$ & $12.9 \pm 0.2$ & $20.6 \pm 1.0$ & 0.64 \\
\hline F11 & $200.1 \pm 0.50$ & $4.0 \pm 0.5$ & $0.75 \pm 0.06$ & $100.6 \pm 0.50$ & $13.0 \pm 0.5$ & $21.1 \pm 0.5$ & 0.65 \\
\hline F12 & $200.2 \pm 0.90$ & $4.2 \pm 0.25$ & $0.68 \pm 0.07$ & $99.9 \pm 1.00$ & $12.95 \pm 0.3$ & $20.9 \pm 1.2$ & 0.65 \\
\hline F13 & $199.9 \pm 0.90$ & $4.1 \pm 0.5$ & $0.73 \pm 0.15$ & $101.6 \pm 1.10$ & $13.1 \pm 0.5$ & $20.35 \pm 1.3$ & 0.66 \\
\hline
\end{tabular}

Table 3: Overall dissolution parameters $(n=6)$ as per central composite design

\begin{tabular}{ccccccc}
\hline Batch & $\mathbf{N}$ & $\mathbf{K}$ & $\mathbf{k}_{\mathbf{1}}$ & $\mathbf{k}_{\mathbf{2}}$ & $\mathbf{Q}_{\mathbf{1 2}}(\%)$ & $\mathbf{T}_{\mathbf{5 0}}(\mathbf{h})$ \\
\hline F1 & 0.4642 & 0.2597 & 1.2837 & 0.0064 & 88.8 & 4.09 \\
F2 & 0.4673 & 0.2535 & 1.2769 & 0.0072 & 87.35 & 4.19 \\
F3 & 0.4697 & 0.2514 & 1.2729 & 0.0077 & 86.72 & 4.23 \\
F4 & 0.4703 & 0.2492 & 1.2693 & 0.0080 & 86.48 & 4.31 \\
F5 & 0.4701 & 0.2461 & 1.2652 & 0.0081 & 85.84 & 4.41 \\
F6 & 0.4761 & 0.2417 & 1.2578 & 0.0093 & 85.6 & 4.48 \\
F7 & 0.4841 & 0.2364 & 1.2509 & 0.0116 & 84.97 & 4.61 \\
F8 & 0.4783 & 0.2376 & 1.2574 & 0.0079 & 84.33 & 4.69 \\
F9 & 0.4724 & 0.2343 & 1.2528 & 0.0084 & 83.69 & 4.82 \\
F10 & 0.4799 & 0.2449 & 1.2651 & 0.0086 & 84.42 & 4.45 \\
F11 & 0.4776 & 0.2426 & 1.2617 & 0.0094 & 85.84 & 4.48 \\
F12 & 0.4757 & 0.2440 & 1.2605 & 0.0091 & 85.62 & 4.45 \\
F13 & 0.4739 & 0.2436 & 1.2612 & 0.0087 & 85.6 & 4.45 \\
\hline
\end{tabular}


the content of either HPMC K4M or CP934P (Table 3).

\section{DISCUSSION}

Tablets (gel-forming matrices) possessing sufficient structure to form a gel layer and they achieve an overall specific gravity lower than that of gastric fluid. TFT of the tablets increased with increase in HPMC K4M content, owing ostensibly to swelling (i.e., hydration) of the hydrocolloid particles on the tablet surface, resulting ultimately in an increase in the bulk volume. The air formed because of bicarbonate and hydrochloric acid entrapped in the swollen polymer matrix and it results in a density less than unity which ultimately results in imparting buoyancy to the tablets [30]. TFT decreases with an increase in CP934P content because of its higher density $(1.76 \mathrm{~g} / \mathrm{cc})$ when compared to that of HPMC $(1.28 \mathrm{~g} / \mathrm{cc})$.

Values of " $n$ " indicate non-Fickian release behaviour for all formulations. The result also shows that with increase in the amount of either polymer the values of $k$ declines. Comparatively much higher magnitude of $k_{1}$ vis-à-vis $k_{2}$ clearly shows that the drug release was predominantly Fickian diffusion, with a very little contribution of polymer relaxation. As viscosity of the gel layer around the tablet increased with an increase in the hydrogel concentration, it decreases the release of drug [31,32]. The gel formed during the penetration of dissolution medium into the matrix consisted of closely packed swollen particles, with more polymer amount, more thick gel formed inhibits dissolution medium penetration more strongly, and resulting in a reduction in the drug release values in $12 \mathrm{~h}$ indicating slower drug release. Therefore the values of $T_{50}$ enhanced markedly from $4.09 \mathrm{~h}$, observed at low levels of both the variables, to as high as $4.82 \mathrm{~h}$, observed at high levels of both the variables, which shows considerable release retarding potential of the polymer. $T_{50}$ shows that at high concentration of polymers the drug release slows besides having initial burst effect.

Various mathematical relationships were generated using MLRA for the studied response variables. High values of $R^{2}$ of the MLRA coefficients for all three responses, ranging between 0.9946 and 0.9999 , vouch high prognostic ability of the RSM polynomials.

$T_{50}=4.44+0.25^{\star} A+0.085^{\star} B+0.018^{*} A^{*} B+0.015^{*} A^{2}-$ $0.03^{*} B^{2}+0.003^{*} A^{2} B+0.027^{\star} A^{*} B^{2}$

$F L T=17.41-9.80^{*} A+3.40^{*} B-2.05^{*} A^{*} B-4.02^{*} A^{2}+1.28^{*} B^{2}-$ $0.65^{\star} A^{2}{ }^{*} \mathrm{~B}-1.00^{*} A^{*} B^{2}$
$T F T=12.29+4.60 * A-1.07^{*} B+0.14^{*} A^{*} B+1.53^{*} A 2+0.15^{*}$ $B 2+0.080^{*} A 2 * B-0.72 * A{ }^{*} B 2$

where $A$ and $B$ are independent variables representing the amounts of HPMC K4M and CP934P in the formulation.

Figure 1 portray the 3-dimensional response surface plots for the studied response properties, viz., $\mathrm{T}_{50}$, FLT, and TFT along with the corresponding 2-dimensional contour plots. $T_{50}$ shows a linear trend in the values of $T_{50}$, markedly increasing with the increment of HPMC K4M levels while With CP934P, the values of $\mathrm{T}_{50}$ tend to increase almost linearly but to a slower extent where at the higher level of CP934P this linear increase in $T_{50}$ vanishes. The same is evident from the corresponding contour plot, showing somewhat inclining linear contour lines, while combination of both shows almost synergistic effect on $T_{50}$ by them. FLT shows a nearly linear ascending pattern for the values of FLT, as the content of HPMC K4M polymer is decreased, the effect being reverse and less prominent with CP934P decrease than with HPMC K4M.

TFT portrays a linear relationship of TFT with increasing amounts of HPMC K4M and CP934P. At low HPMC K4M levels, the value of TFT is less and it increases linearly with an increase in HPMC K4M. On the other hand, the value of TFT at low levels of CP934P is more and with increasing amount of CP934P it decreases; the same is shown by the contour plot for TFT.

The increase in $\mathrm{T}_{50}$ with HPMC K4M was due to its higher hydrophillic ability. Furthermore, the gel layer formed was more viscous resulting to a greater retard in drug release when compared with CP934P.

It was observed that FLT for all tablets was below 35 s regardless of the content of various polymers used, it indicates there is a significant effect of the concentration of polymers (Table 1). Evolution and entrapment of carbon dioxide inside the hydrated polymeric matrices, resulted from the interaction between the gas generating agent $\left(\mathrm{NaHCO}_{3}\right)$ and dissolution medium $(0.1$ mol $\left.\mathrm{L}^{-1} \mathrm{HCl}, \mathrm{pH} 1.2\right)$. This was responsible for the lowering of the density of matrices enabling the tablets to float. From the results of multiple regression analysis, it was found that the dependent variables, $\mathrm{T}_{50}$, FLT and TFT are strongly dependent on the independent variables (Figure 1, Table 4). The correlation coefficients indicate a good fit in the T50\%, FLT and TFT linear plots. Polynomial equations (Eq. 5-7) can be used to draw a conclusion after considering 

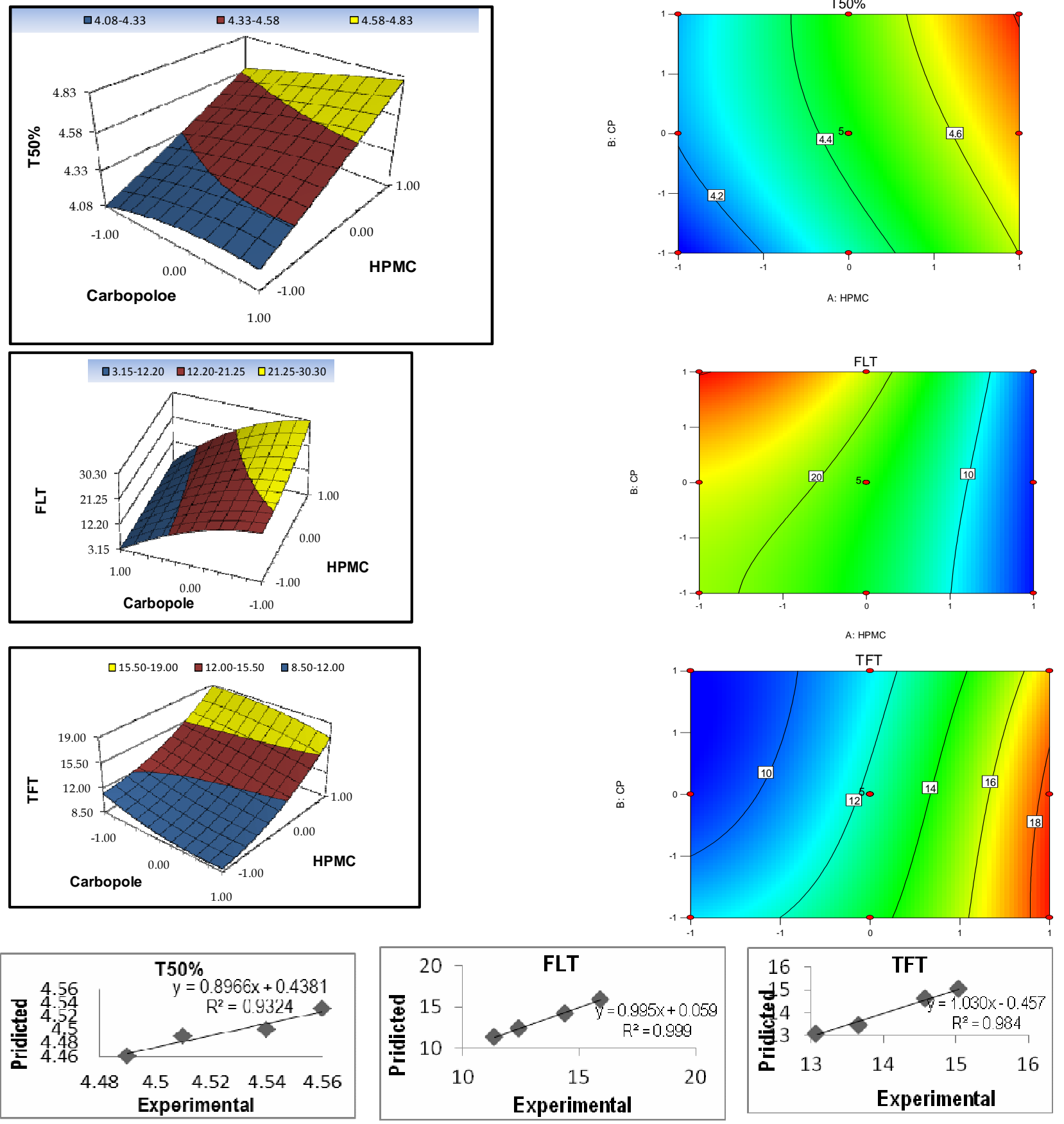

Figure 1: Response surface and contour plots for various variables and the T50\%, FLT and TFT linear plots between observed and predicted values for various variables

the magnitude of the coefficient and the mathematical sign it carries (positive or negative). As the amount of CP934P increased, TFT decreased; this may be due to high affinity of CP934P toward water, which promotes water penetration into tablet matrices, leading to increased density. As the amount of HPMC K4M increased, TFT increased; this is because of increased gel strength of matrices, which prevents escape of evolved carbon dioxide from matrices, leading to decreased density. As the amount of HPMC K4M and CP934P increased,
$\mathrm{T}_{50}$ decreased; this may be due again to high affinity of HPMC K4M and CP934P toward water, which promotes water penetration into tablet matrices, leading to solubilisation of glipizide.

\section{Selection of optimum formulation and DoE validation}

For selecting optimum formulation, the responses observed (experimental) were compared with the expected ones (predicted), 
Table 4: Checkpoint composition and their results

\begin{tabular}{|c|c|c|c|c|c|c|}
\hline $\begin{array}{c}\text { Validation } \\
\text { batch }\end{array}$ & $\begin{array}{c}\mathrm{A} \\
(\mathrm{mg})\end{array}$ & $\begin{array}{c}\mathrm{B} \\
(\mathrm{mg})\end{array}$ & $\begin{array}{c}\text { Response } \\
\text { variable }\end{array}$ & $\begin{array}{l}\text { Prediction } \\
\text { value }\end{array}$ & Experimental values & $\begin{array}{c}\text { Percentage } \\
\text { error }\end{array}$ \\
\hline & & & $T_{50}$ & 4.49 & 4.46 & 0.668151 \\
\hline \multirow[t]{3}{*}{ VCP1 } & 45.16 & 8.52 & TFT (h) & 13.65 & 13.45 & 1.465201 \\
\hline & & & FLT (s) & 14.39 & 14.3 & 0.625434 \\
\hline & & & $T_{50}$ & 4.51 & 4.49 & 0.443459 \\
\hline \multirow[t]{3}{*}{ VCP2 } & 44.8 & 9.6 & TFT (h) & 13.06 & 13.11 & -0.38285 \\
\hline & & & FLT (s) & 15.93 & 15.98 & -0.31387 \\
\hline & & & $T_{50}$ & 4.56 & 4.53 & 0.657895 \\
\hline \multirow[t]{3}{*}{ VCP3 } & 46.96 & 9.12 & TFT (h) & 14.57 & 14.61 & -0.27454 \\
\hline & & & FLT (s) & 12.42 & 12.41 & 0.080515 \\
\hline & & & $T_{50}$ & 4.54 & 4.5 & 0.881057 \\
\hline \multirow[t]{2}{*}{ VCP4 } & 47.32 & 8.4 & TFT (h) & 15.04 & 15.06 & -0.13298 \\
\hline & & & FLT (s) & 11.36 & 11.41 & -0.44014 \\
\hline
\end{tabular}

and a very small percentage error which varied between -0.27 and $1.47 \%$ was found. Linear correlation plots drawn between the predicted and observed responses of validation check points (VCP) and it demonstrated high values of $\mathrm{R}^{2}(0.932$ to 0.999$)$ (Figure 1 , Table 1$)$, indicating excellent goodness of fit $(p<0.05)$. The optimum formulation was selected by trading off various response variables and adopting the following maximizing criteria: $\mathrm{T}_{50}>4 \mathrm{~h}$; TFT>12 $\mathrm{h}$ and FLT<15 s. Upon comprehensive evaluation of grid searches, the formulation (HPMC: $47.32 \mathrm{mg}$ and CP934P: $8.4 \mathrm{mg}$ ) fulfilled the optimal criteria of best regulation of the release rate $T_{50}=4.5 \mathrm{~h}$; TFT $=15.06 \mathrm{~h}$ and $\mathrm{FLT}=11.41 \mathrm{~s}$, this formulation was taken as optimized formulation.

\section{CONCLUSION}

The task of attaining and balancing the required floatation and drug release profile was achieved in the present study using appropriate DoE i.e. CCD with blends of polymers like carbomers and methylcelluloses because of the diverse nature of these polymers. Carbomers, have higher density than the celluloses They are also considered unsuitable to impart buoyancy but useful for controlling drug release while lighter hydrophilic methylcelluloses impart floatation and also influence drug release. Hence, the present work can be considered a platform technology in the manufacture of gastroretentive floating formulations of glipizide.

\section{REFERENCES}

1. Deshpande $A A$, Rhodes $C T$, Shah NH, Malick AW. Controlled-release drug delivery systems for prolonged gastric residence: An overview. Drug Dev Ind Pharm 1996; 22: 631-539.
2. Hwang SJ, Park $H$, Park K. Gastric retentive drugdelivery systems. Crit Rev Ther Drug Carrier Syst 1998; 15: 243-84.

3. Streubel A, Siepmann J, Bodmeier R. Floating matrix tablets based on low-density foam powder: effects of formulation and processing parameters on drug release. Eur J Pharm Sci 2003; 18(1): 37-45.

4. Raval J, Patel J, Nai-Hong Li, Patel M. Ranitidine hydrochloride floating matrix tablets based lowdensity polymer: effects of formulation and processing parameters on drug release. Asian $\mathrm{J}$ Pharm Sci 2007; 2(4): 146-158.

5. Deshpande AA, Shah NH, Rhodes CT, Malick W. Development of a novel controlled-release system for gastric retention. Pharm Res 1997; 14: 815819.

6. Bechgaard H, Ladefoged K. Distribution of pellets in the gastrointestinal tract. The influence on transit time exerted by the density or diameter of pellets. J Pharm Pharmacol 1978; 30: 690-692.

7. Davis SS, Stockwell AF, Taylor MJ. The effect of density on gastric emptying of single and multiple unit dosage forms. Pharm Res 1986; 3: 208-213.

8. Ponchel G, Irache JM. Specific and nonspecific bioadhesive particulate systems for oral delivery to the gastrointestinal tract. Adv. Drug Del Rev 1998; 34: 191-219.

9. Patel JK, Chavda JR. Formulation and evaluation of stomach-specific amoxicillin-loaded carbopol-934P mucoadhesive microspheres for anti-Helicobacter pylori therapy. J Microencapsul 2009; 26(4): 365376.

10. Urquhart J, Theeuwes F. Drug delivery system comprising a reservoir containing a plurality of tiny pills. US Patent 4, 1984; 434, 153, February 28.

11. Chavanpatil MD, Jain $P$, Chaudhari $S$, Shear $R$, Vavia $P R$. Novel sustained release, swellable and bioadhesive gastroretentive drug delivery system for ofloxacin. Int J Pharm 2006; 316: 86-92.

12. Singh $B N, \operatorname{Kim} K H$. Floating drug delivery systems: An approach to oral controlled drug delivery via gastric retention. J Con Rel 2000; 63: 35-259.

13. Das NG. Das SK. Controlled-Release of Oral Dosage Forms-Formulation, Fill and Finish (Supplement to Pharmaceutical Technology); 2003. 10-16

14. Baumgartner S, Kristl J, Vrecer F, Vodopivec P, Zorko $B$. Optimisation of floating matrix tablets and evaluation of their gastric residence time. Int $\mathrm{J}$ Pharm 2000; 195: 125-135.

15. Martindale; The Extra Pharmacopoeia. Anitidiabetics. Royal Pharmaceutical Society, 32 ${ }^{\text {nd }}$ ed.1999: 320. 
16. Shahala J, Fassihi R. Development of a controlled release low doses class II Drug-Glipizide. Int J Pharm 2006, 312: 24-32.

17. Torotora GJ.; Grabowski SR. Principles of anatomy and physiology. $10^{\text {th }}$ ed. New York, John Willey and Sons; 2002; pp 12-20.

18. Boll EW, Sartor G, Melander A, Scherstén B. Impaired effect of sulfonylurea following increased dosage European Journal of Clinical Pharmacology, 1982, 22, (1): 21-25

19. Klausner EA, Lavy E, Friedman M, Hoffman A. Expandable gastro retentive dosage form. J Cont Rel 2003, 90: 143-162

20. Patel JK, Patel RP, Amin AF, Patel MM. Formulation and Evaluation of Mucoadhesive Glipizide Microspheres. AAPS 2005, 6 (1): 49- 55.

21. Chien YW. Novel drug delivery systems. $2^{\text {nd }}$ ed. New York: Marcel Dekker Inc; 1992. 171-176p.

22. Rosa M, Zia H, Rhodes T. Dosing and testing in-vitro of a bioadhesive and floating drug delivery system for oral application. Int J Pharm 1994; 105: 65-70.

23. Dorozynski $P$, Jachowicz $R$, Kulinowski $P$, Kwiecinski $S$, Szybinski K, Skorka T, Jasinski A. The polymers for the preparation of hydrodynamically balanced systems-methods of evaluation, Drug Dev Ind Pharm 2004; 30 (9): 947-957.

24. Prabhakara $P$, Harish NM, Gulzar AM, Brijesh $Y$, Narayana $C R$, Satyanarayana $D$, Subrahmanayam EVS. Formulation and In Vitro Evaluation of Gastric Oral Floating Tablets of Glipizide. Ind $J$ Pharm Edu Res 2008; 42(2): 173-183.
25. Indian pharmacopoeia 2007, Government of India, Ministry of Health and Family welfare, The Indian Pharmacopoeia Commission, Ghaziabad, 2007: 1167-1168.

26. Singh B, Singh S. A comprehensive computer program for study of drug release kinetics from compressed matrices. Indian J Pharm Sci 1998; 60: 358-362.

27. Singh B, Kaur $T$, Singh $S$. Correction of raw dissolution data for loss of drug during sampling. Indian $J$ Pharm Sci 1997; 59: 196-199.

28. Higuchi T. Mechanism of sustained-action medication: theoretical analysis of rate of release of solid drugs dispersed in solid matrices. J Pharm Sci 1963, 52: 1145-1149.

29. Korsemeyer RW, Gurny R, Doelker E, Buri P, Peppas N. Mechanism of solute release from porous hydrophillic polymers. Int J Pharm 1983; 15: 2535.

30. Smart JD, Kellaway IW, Worthington HE. An in-vitro investigation of mucosa-adhesive materials for use in controlled drug delivery. J Pharm Pharmacol 1984; 36: 295-299.

31. Perez-Marcos B, Iglesias R, Gomez-amoza JL, Martinez-Pacheo $R$, Souto $C$, Conchiero $R$. Mechanical and drug release properties of atenolol-carbomer hydrophilic matrix tablets. J Control Rel 1991; 17: 267-276.

32. Levina $M$, Ali $R$, Siahboomi $R$. The Influence of Excipients on Drug Release from Hydroxypropyl Methylcellulose Matrices. J Pharma Sci 2004; 93(11): 2746-2754. 